\title{
Study on Ecological Context and Eco-compensation Mechanism of Basic Education Informatization in Northwest Minority Areas
}

\author{
Minjun Cai, Yali Hu, Xiaotao Li, and Haoyin Lv
}

\begin{abstract}
In the education informatization ecosystem, the ecological development of elementary education informatization in northwestern China is extremely uneven. Besides, this problem has seriously affected the coordination and balance of the education informatization ecosystem's hierarchy and regional structures in China. Therefore this research firstly tries to analyze the realistic context and development characteristics of the education informatization in Northwest minority areas in hope of putting forward a corresponding compensation mechanism for this. And secondly manages to improve the energy and power of the elementary education ecological system in Northwest minority areas, then finally to promote the development of our country's elementary education informatization ecosystem in a balanced way.
\end{abstract}

Index Terms-Informatization, minority nationality education, problems, strategies.

\section{INTRODUCTION}

The education informatization in Northwest ethnic regions is not only a region's education problem. From the perspective of system theory, it is a part of education system, its change and development is associated with the macroscopic system of education, and is also closely related to the whole advancement work of education informatization in China. According to the principles of education ecology, the occurrence and development ways of all the elements within the education system are in a "ecosystem" or "ecosphere" in which a variety of "physical, social, symbol" and the like elements interacted with each other( van Lier, 2010:4) [1]. In other words, all sorts of education phenomena and the related subjects are associated with certain ecological context naturally, socially, normatively, psychologically, and so forth. Besides, all different kinds of state with the occurrence and development of the education informatization in Northwest ethnic regions are linked to the macroscopic ecological context on the one hand. On the other hand it depends on the

Manuscript received March 10, 2015; revised August 19, 2015. This work was supported in part by the Research Project of Institution of Higher Education in Gansu Province under Grant 2013B-088.

Minjun Cai was with the Northwest Normal University, Gansu, Lanzhou, 730070, China. He is now with the Department of Education Technology of Northwest Normal University, China (e-mail: caimj916@126.com).

Yali $\mathrm{Hu}$ and Xiaotao $\mathrm{Li}$ are with the Northwest Normal University, Department of Education Technology, Lanzhou, 730070, China (e-mail: 1132520569@qq.com,1123792925@qq.com).

Haoyin Lv is with the Longdong University, the Department of Information and Engineering, Gansu, QY, 745000, China (e-mail: zhaolhy2015@163.com). structure, states and circulation mechanism of regional education ecological subsystem, etc.

This study attempts to analyze the ecological context of the education informatization in Northwest minority areas from the perspective of education ecological system, and then propose a corresponding compensation mechanism. On the one hand, this study is helpful to establish a corresponding compensation mechanism to improve the ecological structure of the elementary education informatization in Northwest minority areas; On the other hand, through the improvement of the ecological environment of elementary education informatization in Northwest minority areas, the elementary education informatization ecosystem in our country will be promoted with sound progress macroscopically.

\section{ECO-CONTEXT OF ELEMENTARY EDUCATION INFORMATIZATION IN NORTHWEST MINORITY AREAS}

Education ecology is the states and features that education survived and developed, is the combination of the education system and its surroundings. From the perspective of ecological context we can get a deeper understanding about education, that is " put all kinds of Education institutions and structures into contact with each other, into social connections in which it was sustained and protected, and produce reactive force." (Cremin, 1976:36) [2]. In other words, education ecology is firstly a ecological system of education that composed by education and society, as well as a relationship between education and nature-related systems. Secondly, the balance and imbalance of ecological education together with the differences and changes of the system structure determined the operation way and result of education ecological system. And finally the evolution and circulation of education ecosystem mainly depends on the ecological environment and the structure function of education. In one word, the effect and function of education ecological environment and education ecological structure influence the change and development of the education profoundly.

Because the elementary education informatization ecosystem in northwest ethnic regions is influenced by social ecology, especially the economic ecology, it's ecological subsystem existed a low-level operating problem for a long time. The education informatization in northwest ethnic areas is at a junior development situation and has been marginalized in China's education informatization ecosystem no matter in terms of its geographical distribution (education in west and mid-east region of China) and level (basic education and higher education), or subject. 


\section{A. Low-Level Operating Ecological Subsystems of Education Informatization}

According to principles of education ecology, the forms that energy flow transfers among education ecological systems are diversified and the distribution of energy in the ecological system will be a structural imbalance, thus a situation in which the enrichment, or failure, or the lack of energy will appear. For a long time, situated in the economic underdeveloped regions the education informatization in northwest regions, especially in rural areas and ethnic minority areas have difficulty in sufficient input or in other words, it's system energy is insufficient. For example, a survey in five cities of Gansu Hexi suggested that on average 18.5 students have an access to use computers, which is far below the national average of 13:1." (Z. M. Li, 2013) [3] Due to the narrow space of education direct consumption, the indirect education consumption ability is low, which means the quantity and quality of the corresponding education managers and education a practitioner are very limited. Therefore the insufficient investment and the lack of resources leaded to the low-level operate of regional subsystems.

In terms of regional variables, the energy distribution of elementary education in northwest ethnic regions is not sufficient in structure. But the matter that whether material flow and energy flow are reasonable or not depends on its internal flow, namely, the balance state where material flow and energy flow transfer within the subsystem. The limited education informatization resources allocating in northwest China, makes the elementary education informatization resources in rural areas and ethnic minority areas scarcer. In terms of ecological position, basic education is in the bottom of education ecology cone, and is an important part for structure construction and knowledge exchange of the education ecological pyramid. Hence when we are allocating the resources of all parts of system structure, the basic education should occupy a larger proportion (Q. X. Jiang, 2012) [4]. Although under the situation where the the overall resources are insufficient, the elementary education informatization in Northwest areas shares a more limited quota. As an example, "rural distance" network receiving, download and some distributed DCs were not applied effectively due to the scarce and aged terminal equipment. The quantity of computers and other teaching equipment in rural schools is far from superiors' requirements, thus, as a result of this the teacher gradually lost faith in the application of information technology. As a result, the elementary education informatization in the bottom of the cone is hard to play the basic effective function, leading to low-level operating elementary education informatization ecosystem in the northwest minority area become much weaker and its operation mode appears a more lack of complementary functions.

\section{B. Level Succession Disorders of Education Informatization Ecology}

The system imbalance caused by uneven distribution of resources and inadequacy of ecological energy, not only gave rise to resource starvation of elementary education informatization in Northwest minority areas, but also created the losses and disorders of education system in its level succession. Disorders of the level succession of education in Northwest minority areas are mainly manifested in the efficiency of elementary education informatization. Namely it is mainly reflected in the function that education informatization possessed in promoting the quality of local basic education. For instance, because education informatization is unable to provide enormous help for the region's basic education, it can't promote the rapid development of elementary education informatization in return effectively. At the same time, since audio-visual education teachers and teachers of rural distance education have no chance to be selected as excellent teachers, they lack inspiration and enthusiasm in work. Thus they always work in the field of equipment management and technical services which without innovation, let alone to make information media resources functional in leading its application (F. Y. Gao, J. H. Shen, 2013) [5].

Disorders of level succession are important factors that restrict the virtuous cycle of education information ecosystem in Northwest minority areas. At the same time, it also restricts and affects the development and circulation the national elementary education ecological macroscopic system. The relationship between factors and factors, subsystems and subsystems in education ecosystem is not simply a linear structure. In terms of the cohesion of basic education and higher education, urban and rural areas links eastern and western areas in a vertical and horizontal cross way. Therefore the succession disorder of elementary education informatization system in Northwest minority areas is bound to affect the level succession of the national elementary education informatization system. In ecological sense, the most direct impact is intelligent flow (horizontal). If it transfers in a crossed way, it will be very hard to realize a virtuous cycle. More specifically, it will not able to achieve the healthy and effective operation of circulation mechanism between education input and output (investment and yielding ).

\section{Functional Disorder of Ecological Culture of Education Informatization}

A region's implicit culture, to a large extent influences the potential education eco-environment in this area, and then affects the explicit effect form of education.

Functional disorders of ecological culture of education informatization in Northwest minority areas are mainly manifested in the following two aspects:

1) Elementary education informatization is on the brink of cultural ecology

Most of the rural population is distributed in the western regions of China. At the same time, the western regions are also the main areas that minorities live in with more than $70 \%$ of the minority population inhabited in southwest and northwest. For minority students, their parents' habits have a deep influence on them. Their parents are accustomed to using traditional media tools to study instead of using internet and computer. So in the eyes of their parents, studying on the internet and learning with a computer are unnecessary things in the process of study. Even "some teachers have a 'feeling of fear' for computer and network. They objected to and even 
refused to accept the information technology by abandoning and setting the advanced education methods aside and ignored them." Due to the influence of the backward natural ecology and social culture ecology, the importance of the education informatization has not been paid much focus in the northwest minority areas. As a result of this, the northwest regions don't have a good atmosphere to encourage the use of information technology teaching means. Many parents believe that it is not a good way for students to complete their homework done by network. The reason behind this is that parents think it will affect students' learning effect instead of being helpful in improving the students' learning achievement No matter it is teaching management personnel, teachers or students, they all didn't understand education informatization fully. In addition because of the limited teachers and equipment in a lot of schools, the information technology courses are not run very well, which makes information technology teaching difficult to obtain an equally important position as main courses like Chinese and maths. Education informatization is in the awkward position of "marginalized in school ecology and defamiliarized in community ecology."

2) The understanding of education informatization is confined to the instrumental value of information technology disciplines

The effective evolution and succession of education ecology are both a structural fluctuation, and influenced by the unstructured factors, namely education thoughts and ideas, as well as the related teaching plan and method, etc. In the education informationization, autonomy and innovation are widespread cultural phenomenon in the process of information technology application. However due to the academic pressure, the basic education of northwest ethnic regions aims at improving students' scores by using education informatization, or they just recognize information technology as an operation skill, while ignoring its prominent role in training students' autonomous learning ability and the innovation spirit.

In northwest minority areas, represented by concept of education, and the informal ecological culture that accompanied by poor economy imprisoned the ideas and behavior of people. Besides the negative impact of this kind of informal institutional constraints on the basic education can not to be underestimated. In short, firstly the poor culture cannot form humanities environment required by the education development; secondly negative thoughts and backward ideas make education lacks the necessary motivation; thirdly the dislocated value orientation seriously restricts the process of education informatization.

\section{THE SHORTAGE OF DRIVING FORCE OF GROWTH IN EDUCATION INFORMATIZATION ECOSYSTEM}

The imbalance and incoordination of the ecosystem of elementary education informatization origin from factors in many aspects. These factors include historical and social ones, but at the same time, teacher, as the main body of self-organizing energy in education ecosystem, is also the crucial factor.

In northwest ethnic regions, the development of middle and primary school teachers' ability to apply informatizational teaching in the local ecosystem of education informatization plays a role as the central driver. However, the ecologocal condition at present makes it produce some characteristics that restrain the development of educational ecology, mainly in two aspects as follows:

1) The unipolarity of transmission of talents flow results in the shortage of human resources in regional system.

The lack of professional teachers whose major is IT is one of the main reasons that restrict the effective development of education informatization in Northwest ethnic regions. In fact, a normal and regular talent flow is the organic state of the development and variation of educational ecosystem. Unfortunately the talent flow in Northwest ethnic region is not energy flow mechanism of exchanging pattern, but functional energetical unipolar flow to the eastern developed areas and cities. For one thing, this phenomenon makes Northwest minority areas' whole informatizational education suffering the shortage of teachers. For another thing, the emigration of teacher in city school to other regions accordingly causes the backbone IT teachers' immigration in rural and ethnic areas to the city.

Due to the insignificant position of IT curriculum, many teacher under the restriction of promotion choose to change their job and just quit office. At the same time, the new member replenished to the posts is almost green hands or dispatched from other jobs provisionally. What is more, the unidirection of talent flow in western rural and ethnic regions has a special pattern-flow of interdisciplinary studies. Workers of education informatization in Northwest ethnic regions flow in as the non-professional, but flow out as the professional, which is extremely bad for people to improve their sense of identity towards the professional degree of education informatization. From the perspective of educational ecosystem, with higher degree of unidirection of energetical transmission comes weaker endogenous power and worse imbalance of system.

2) The shortage of endogenous energy and the distribution imbalance of inner structure of elementary education ecology.

As far as the groups of teachers, education background and specialty structure are the important components of educational group ecological structure. In general, there exists the phenomenon of imbalance in the structure of teachers in Northwest ethnic regions' elementary education informatization. To be more specifically, its imbalance is mainly manifested in the following three aspects:

The first is the imbalance of education background structure.

There are gaps between the rate of reaching the standard of education background and the demand of new curriculum. According to the statistics declared by education management department, the education background of IT teachers in all schools almost reaches the demand of The National Teacher's Law. However, what should be explained is that most of teachers' bachelor degree is got through teaching by correspondence, or self-taught examination. Besides there are a great number of middle school IT teachers who have bachelor degree that graduated from the regional 2nd undergraduate normal colleges in county town and rural areas below county. Teachers of other subjects just only pay 
attention to the improvement of degree, and are lack of the specialized education of informatizational teaching ability. This indicates the imbalance of education background levels of IT teachers and the biggest barrier carrying out new curriculum reform in Northwest ethnic regions - the problem of teacher resources - the lack of IT teachers and teachers whose technical competence is weak.

The second is the imbalance of specialty structure.

The reasons behind this view can be concluded as following two aspects. For one thing, the interdisciplinary grafted teachers do not only lack of subject teaching approach. For another thing in actual situation, teachers team of low level education background together with teachers who is not professional in certain field could neither adapt the demand of educational reform to teachers' ability to apply information technology, nor have a larger space to realize their own development without too many restrictions. Analyzed from the aspect of educational ecosystem, the imbalance between education background structure and specialty background is an important factor that restrains the endogenous power of the system.

According to the principle of ecological pyramid theory, teacher group of the elementary education in educational ecosystem should be positive pyramid in the respects of pyramid of number and that of energy. In other words, the teachers in elementary education system should be at the bottom of the pyramid whether in quality or in quantity. From this point of view, the endogenous power of development of informatization of middle and primary school teacher is in shortage, which restricts the effective evolution of education informatization ecology.

The third is the deviation of teaching cognition

Influenced by the overall cultural awareness of the elementary education informatization in Northwest ethnic regions, teachers have an one-sided and unitary cognition. The Technology Curriculum Standard for Full-time Compulsory Education of Ordinary Senior High School stipulated that technology curriculum is a practice-based, highly comprehensive, creative-focused and a scientifically and culturally confluent curriculum (Ministry of Education, 2003) [6]. The curriculum objectives reflect the value orientation of comprehensiveness, sociality, humanity and practicality in IT education. At the same time, as it ensures that students can improve cognitive structure and develop the ability to comprehensively adopt information technology. It also aims at advancing students' understanding of culture, promoting their communication and expression skills, ameliorating their ways of learning and promoting their lifelong development. As we all know, teachers' information technology ability is an important factor in ecological education informationization. However, in practical context teachers structure is difficult to compensate for the fragile education informationization ecology in Northwest minority areas effectively. What's more, it even can't promote the region's normal evolution of education informatization ecology.

IV. The ECOlOGICAL COMPENSATION MECHANISM OF ELEMENTARY EDUCATION INFORMATIZATION IN NORTHWEST ETHNIC REGIONS
Education ecosystem is a dynamic structure which can adjust initiatively through patching when imbalance appears in the system. What's more, the outside world bails out requisite money, facility, personnel, and principles and policies to education, meanwhile education outputs various kinds of talents and technological fruits. This kind of exchange of substance, energy, information and all that of education and external eco-environment can make the education ecosystem keep orderly and balanced [7].

\section{A. The Compensation of Educational Policies}

Government regulates and allocates educational resources and optimizes educational ecology rationally through educational policy instruments. From the regional policies, we should increase the guidance and instruction of Northwest ethnic regions' normal universities, confirm the operating thought and development orientation of Northwest regions' normal universities, give more support to these universities and make the universities orient the cultivating aims and development thoughts in Northwest regions, especially in the course standard of villages and ethnic groups areas. From the funds, we should enlarge the payment of elementary education and ethnic education by central education finance, try to set up the mechanism separating education informatization fees and educational administration fees, ensure the specialized fees for education informatization. At the same time, we should stabilize the information technology faculty of elementary education in Northwest ethnic regions through educational policy inclination (such as salary, or elevating the educational background plan).

The compensation of educational policy can be divided into direct compensation and indirect compensation. Except for the direct compensation of educational expenses and educational facilities, administrative support can become the way of indirect compensation. For example, on the basis of national training plan, we can cultivate and support the elementary education informatization teachers' engineering of national regions, etc. Besides national policy compensation, local education administrative departments at all levels and local colleges and universities could search multiple outside aid tactics and methods, such as provincial government and municipal government of Qinghai Province raise the funds of program construction to launch pilot project of 4 counties' Class Access to ICTs. By the end of 2010, we have built 4500 CD teaching pilots in 4 counties like Huangyuan, Huangzhong, Ledu, Datong so as to share the Eastern course teaching materials. Furthermore, the modern distance education project of rural elementary and middle schools is mainly aimed at a vast territory with sparse population, scattered layout of schools. So, to think about it at this point, utilizing network technology to realize the sharing of high quality education resources is a good choice.

\section{B. The Compensation of Cultural Concept}

Educational culture ideals were considered as a potential ecological awareness to profoundly affect the process of education information in a region or a university. Educational culture attaches great importance on both intracurricular class and extracurricular class. The potential and invisible consciousness of extracurricular class is often more expansive soil for classroom environment, "class context inoculates in 
schools, communities, families, cultural context, and the effect of this kind of classroom context is obvious." (Hamilton, 1983) [8] The development of education information was restricted by the awareness problem of education information in Northwest ethnic region and relevant course marginalization tendency of education management information technology.

The education information concept's backwardness in Northwest ethnic regions is not completely on account of economic backwardness. Educational concepts and the whole regional culture and educational levels are mutual relationship. Pedagogical economics think education and economy are interchangeable function relation of two variables, both are exogenous and endogenous variables. In different historical periods and different social-economic pattern, economy also could have different relations with (culture) education. In developing countries, especially the relatively backward areas of developing countries in economy, "Economy First" is usually the regular thought. But to a certain extent (a period of time, a certain phase), the effects of ideology "soft power" decide the significance of "education first" . As far as the present relationship between Northwest minority areas' economy and education, the two are positive correlation, and in such condition for a long time. Northwest ethnic regions' elementary education information should strive to get more financial support, meanwhile trying to get rid of their own educational concept fetters, and searching for the correct development thought and mode of education information under the condition of economic and ecological vulnerability. We should protect and guide this kind of education, converting it into the internal power of education information development to make up the negative effects caused by resources shortage and improve the ethnic and regional identity of education information, fundamentally changing the education concept. Currently in Huangyang Chuan town, Gulang county, Gansu Province, the mode of "the school leading township" set up by Huangyang Chuan vocational middle school is a part of "thousands of villages and townships" project, so as to enhance the information application consciousness. This project has already owned 156 member school such as Tianzhu county ethnic middle school, Huinong area Hui nationality middle school, Erdos Hangjin Qi Mongolian middle school and so on, and accessed the Internet and established the "Digital classroom". On the basis of setting up information platform, "thousands of villages and township" project aims at making the Internet step in villages, and is spread by the local middle schools. Through the whole region promoting information levels, "the school leading township" will further improve western ethnic regions' cognitive level of education information application.

\section{The Compensation of Academic Development}

The compensation of academic development means teachers combine with their own characteristics of self-organization regulation method under the condition of limited education ecology, also it's a further improvement and development of teachers in the aspect of professional level and information education teaching ability. For the main content, academic development mainly can be divided into two aspects.
1) The development of professional consciousness

Famous curriculum specialist Stenhouse (Stenhouse, 1985) [9] thought the core of curriculum reform is teacher. The development of teachers, especially the professional development, is the important approach to the whole education information system's self-renewal and the supplement of knowledge. For the information technology teachers in Northwest ethnic regions and other subject teachers. The key of professional development is not only how to develop, but the importance is whether there exists the self-development consciousness and capacity of independent development. Consciousness is the prerequisite to promote the professional development [10]. Due to teaching conditions, most teachers lack the development consciousness and the prerequisite of professional development. Meanwhile, even if they have a certain consciousness of independent development, yet lack of the capacity of independent development. This requires teachers and relevant management sectors actively cultivate teachers' information consciousness and capacity of independent development, effectively achieving the transformation of professional levels and capacity.

2) The development of informatization educational and teaching capacity

Generally speaking, informatization education and teaching capacity includes ordinary education and teaching capacity and informatization curriculum teaching capacity. Mishra and Koehler fully emphasized importance of combining "technology, teaching method, content knowledge" in the knowledge framework of TPACK raised in 2006. Because of low-levels of education of Northwest ethnic regions' teachers and most of them lack of educational background, they need the supplement of professional education if the aspect of teaching practice capacity. Except for the ordinary educational theory knowledge, teacher also should master the knowledge of subject teaching under the condition of informatization, and combine with the specific subject background, fully giving play to the advantage of information technology.

Teachers' academic compensation is the most powerful approach of ecological compensation mechanism. Through improving the specialized knowledge and informatization education teaching practice capacity, teachers can effectively change their own survival ability, and improve the system's energy.

\section{CONCLUSION}

The construction of ecological system is gradually perfected in the process of compensation. Through policy compensation and the balance of system structure such as internal material flow and energy flow, we can effectively promote the coordinated development of education system. To analyze this from the perspective of system dynamics, we can say its process of evolution is driven by internal power system and external power system. The compensation of policy is the foundation of external dynamics, the compensation of cultural concept is the intrinsic motivation mechanism, and the compensation of academic development 
is the core of power dynamics. The dynamic system of education informatization is an interaction of associated body. The occurrence of each element in the education informatization system is influenced socially and environmentally. In the context of ecological education informationization in the ethnic regions of northwest, the development of elementary education informatization on the one hand depends on the external effect of macroscopic system, namely, the "heter-organization" of ecosystem evolution; On the other hand it also depends on the internal control of regional subsystem, namely the role of "self-organization" of ecosystem evolution. Ecological compensation mechanism not only can make up for problems such as the efficiency of system elements and the shortage of internal impetus driving of teachers, but also can optimize the ecological structure of the total system of education informationization.

\section{REFERENCES}

[1] L. Lier, "The ecology of language learning: Practice to theory, theory to practice," Procedia Social and Behavioral Sciences, pp. 2-6, March 2010.

[2] L. A. Cremin, Public Education, The John Dewey Society, 1976.

[3] Z. M. Li, "The present situation investigation and strategy research of education informatization in northwest areas - Take schools in He Xi five cities, Gansu Province as example," Primary and Middle School Technology Education, vol. 11, pp. 3-6, September 2013.

[4] Q. X. Jiang, "A study of eco-context and eco-compensations for FL education in west China," Foreign Languages in China, vol. 6, pp. 4-10, September 2012.

[5] F. Y. Gao and J. H. Shen "New thinking of the development of education informatization in ethnic minority areas - To take Wuchuan Gelao and Mao Nationalities' autonomous county in Zunyi of Guizhou province as an example," China Educational Technology, vol. 9, pp. 35-38, 2013.

[6] L. Ye, Education Introduction, Beijing: People's Education Press, 1991, p. 148.

[7] D. F.Wu and W. W. Zhu, Education Ecology, Nan Jing: Jiangsu Press, p. 93,2000

[8] S. F. Hamilton, "The social side of schooling: Ecological studies of classroom and schools," Elementary School Journal, vol. 4, pp. 313-314, 1983.

[9] L. Stenhouse, Research as a Basis for Teaching. Oxford: Heinemann, 1985 .

[10] B. Ailey et al., Pursuing Professional Development: The Self as Source, Beijing: Foreign Language Teaching and Research Press, 2004.

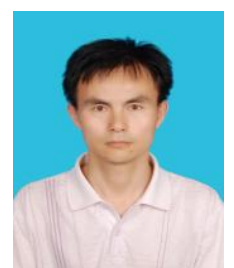

Minjun Cai was born in Gansu, Qingyang city in September 1973. He received a bachelorer's degree of education in 1998 and a master's degree of education in 2003 in Northwest Normal University. At present, he is studying in the Department of Education Technology of Beijing Norman University for the doctor's degree.

Since 2003, he has been a teacher, an associate professor in Northwest Norman University. His openly published papers are above 30, including a book Computer Aided Education Measurement and Evaluation, Beijing: China Water Power Press, 2010. The current research interests focus on curriculum development and evaluation, learning science and technology and the basic theory of education technology.

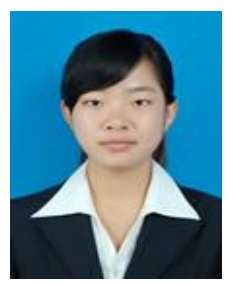

Yali Hu was born in Gansu, Dingxi city in January 1992. She is a first-year graduate student in Northwest Normal University. In 2014, she earned a bachelor's degree of arts in Xi' an University of Arts and Science. From 2014 to now, she studies in Northwest Norma University, the Department of Education Technology, majoring in education technology. She mainly studies the application of educational information technology. 